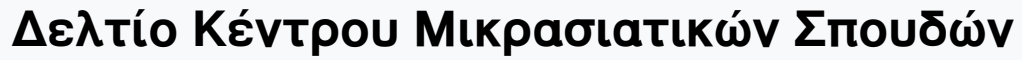

Tó 11 (1995)

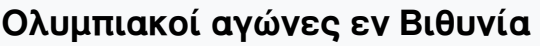

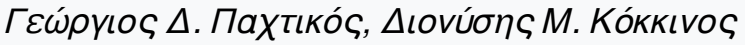

\section{$\Delta \mathrm{E} \Lambda \mathrm{TIO}$}

doi: $10.12681 /$ deltiokms.70

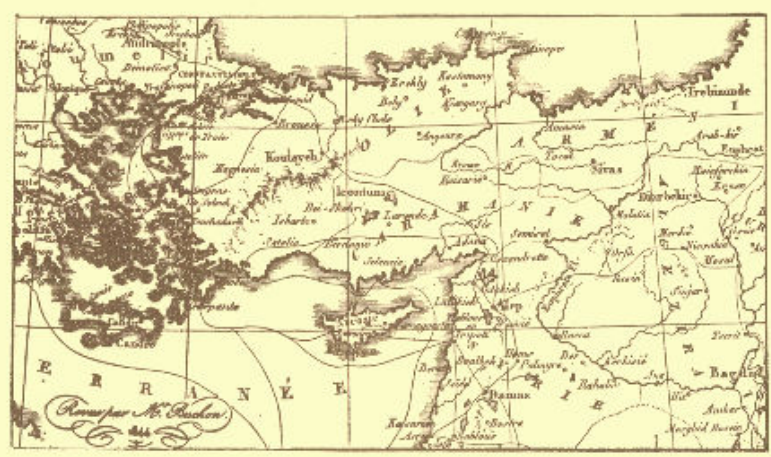

\section{(9) $\odot \otimes \odot$}

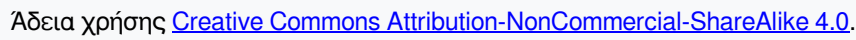

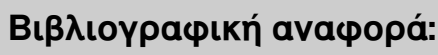

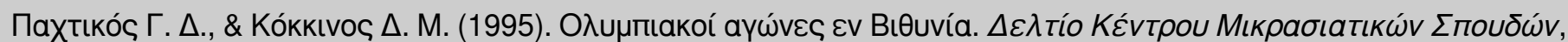
11, 433-454. https://doi.org/10.12681/deltiokms.70 
ПАРАРТНМА 


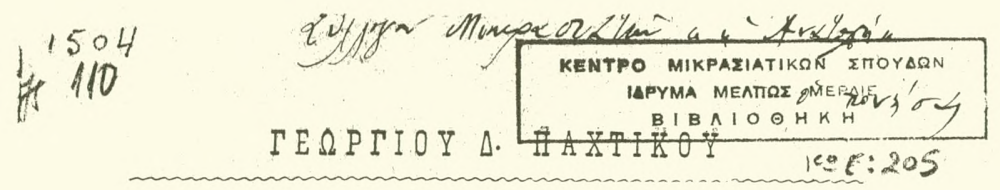

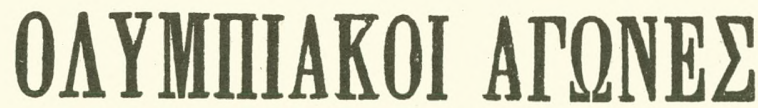

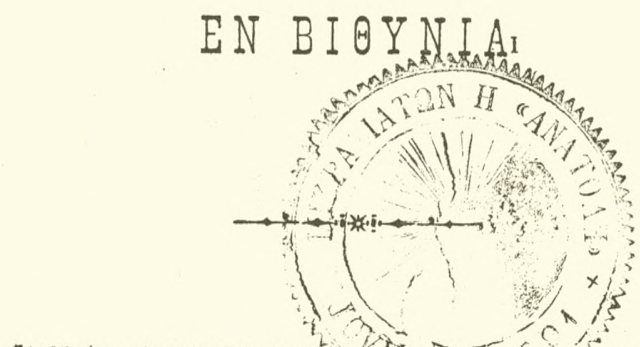

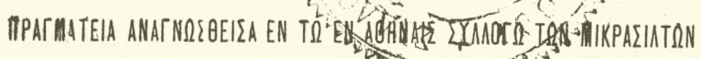
"H ANATOXF"

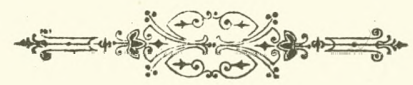

\section{EN AOHNAIS}

EK TOY TYIOГPAФEIO А 1893 



\title{
A DIEPOYTAI
}

TI! AEIOTIMQI TPOEAPQI TOY EYMMOTOY TON MIRPAEIATIN "ANATO $\Lambda \mathrm{H}$ " KYPI $\Omega$ !

\section{MAPTAPITH ${ }^{I}$ EYATГEAISH}

\author{
○ ПTONHEAE
}




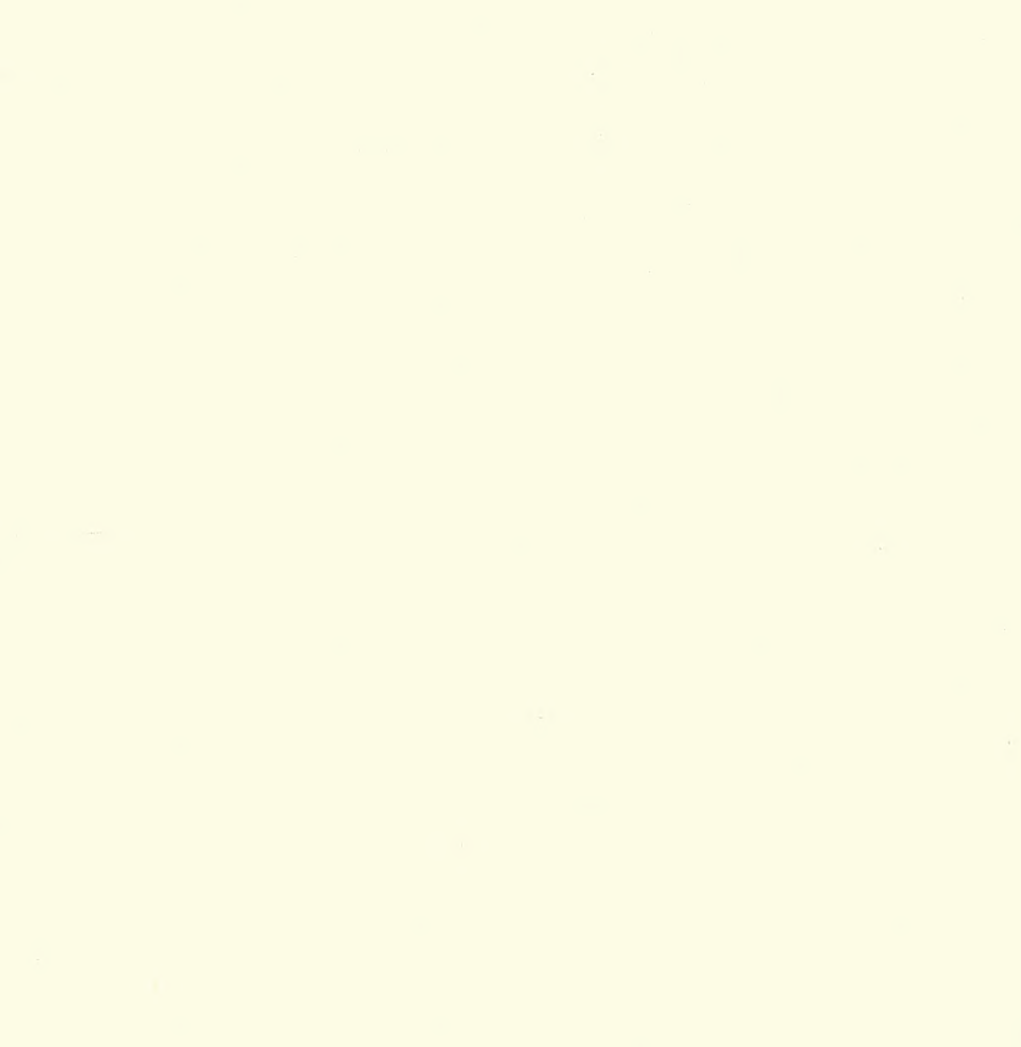




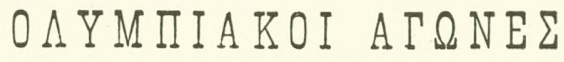

\section{EN BI@YNI Ai(')}

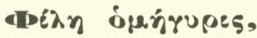

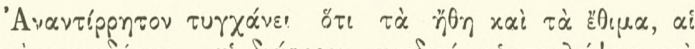

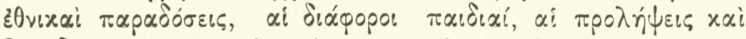

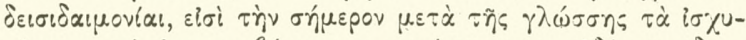

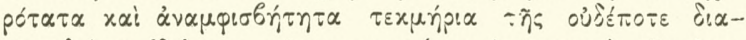

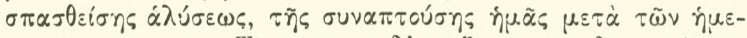

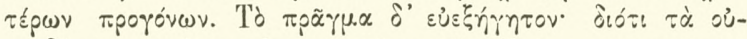

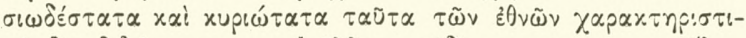

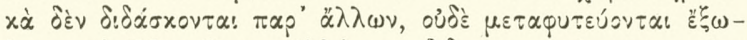

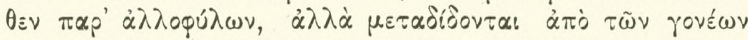

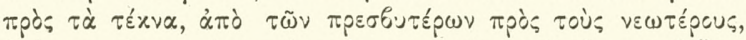

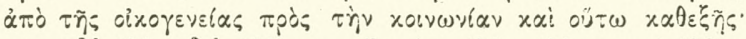

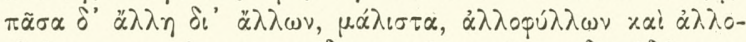

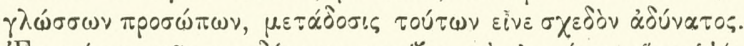

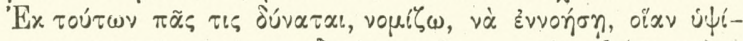

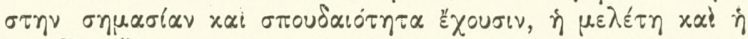

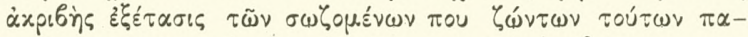

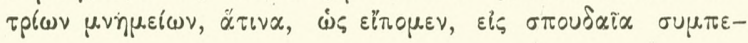

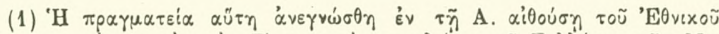

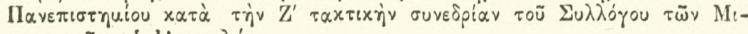

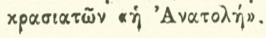




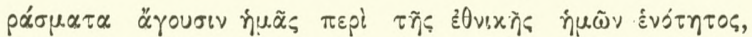

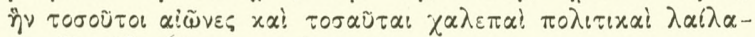

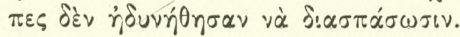

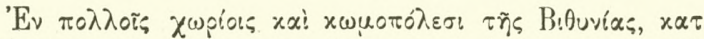

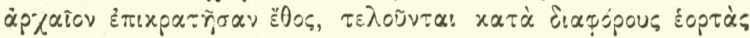

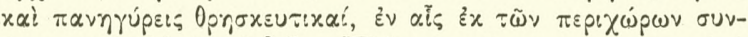

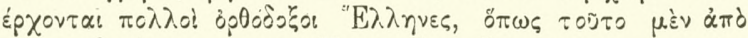

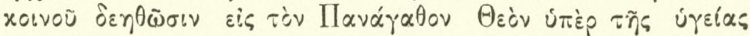

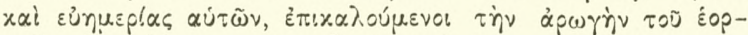

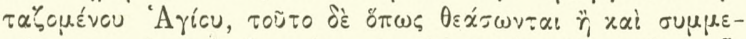

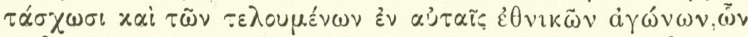

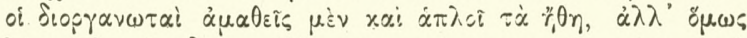

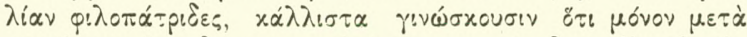

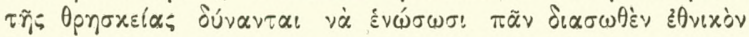
$x \varepsilon\llcorner\mu$.

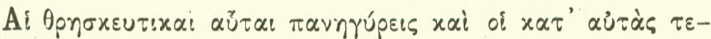

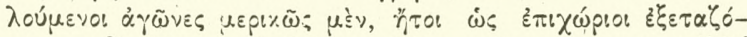

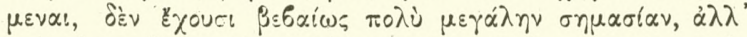

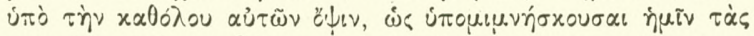

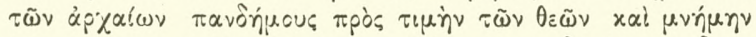

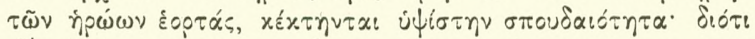

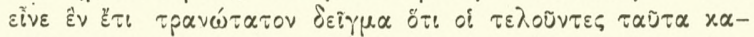

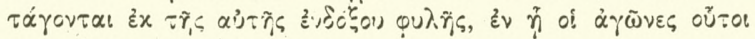

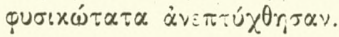

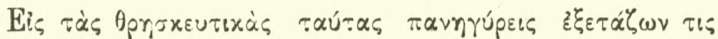

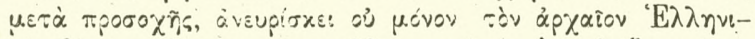

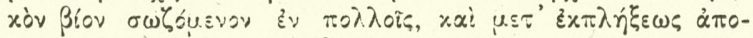

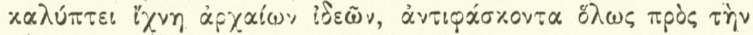

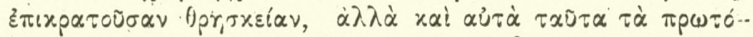

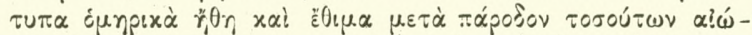

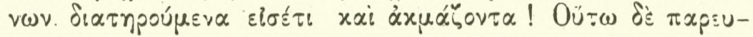

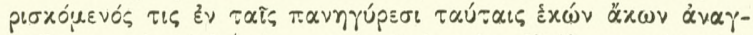

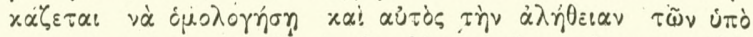

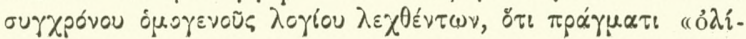




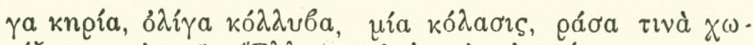

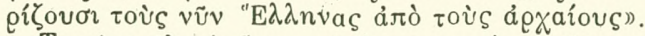

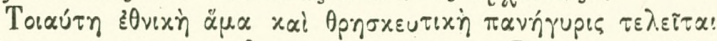

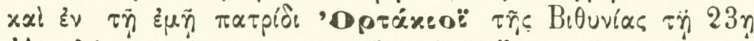

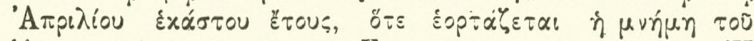

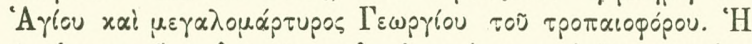

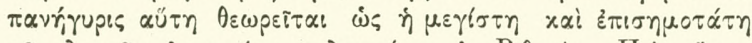

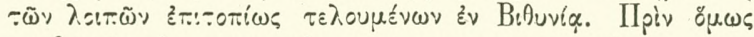

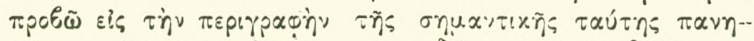

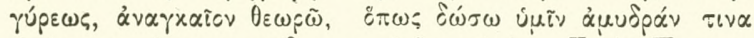

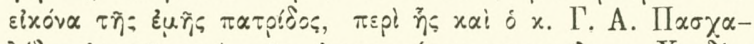

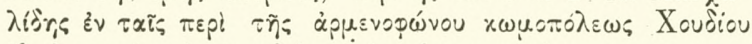

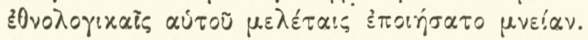

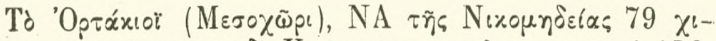

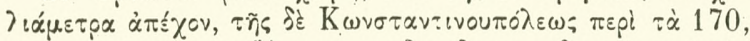

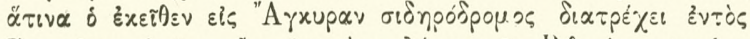

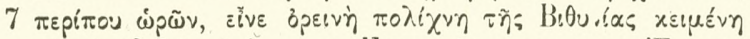

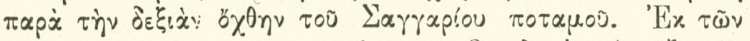

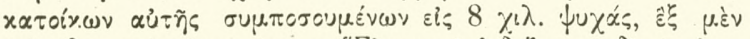

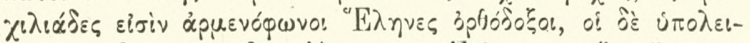

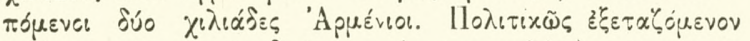

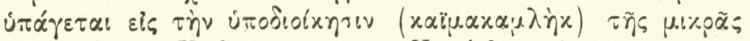

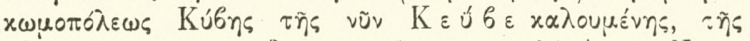

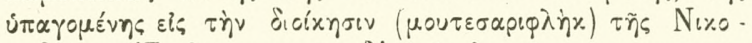

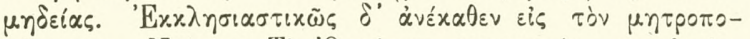

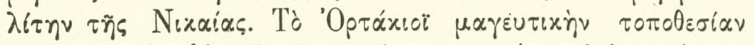

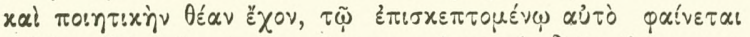

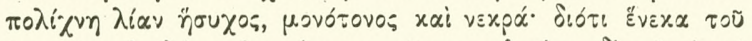

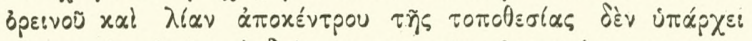

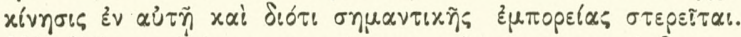

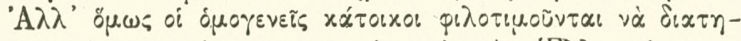

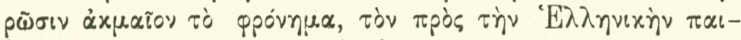

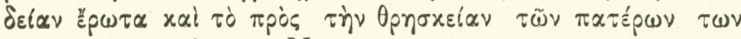

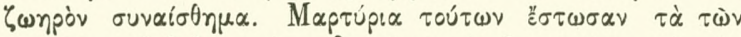

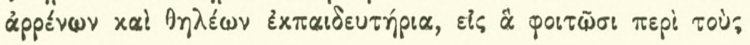




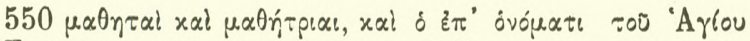

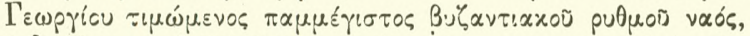

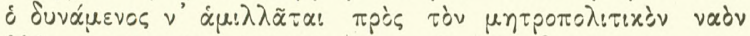

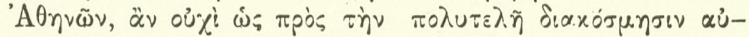

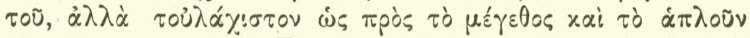

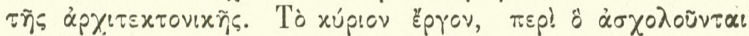

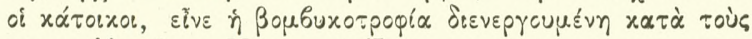

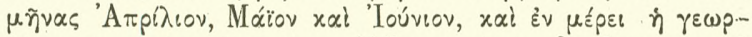

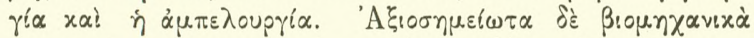

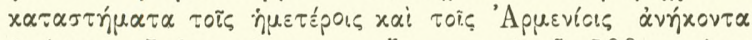

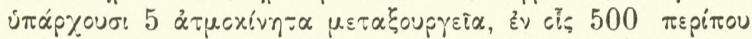

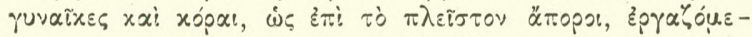

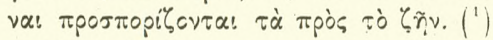

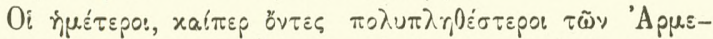

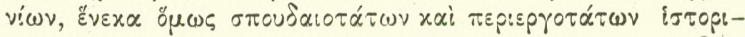

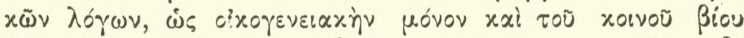

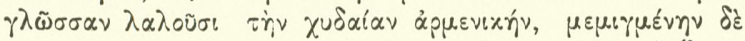

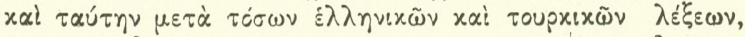

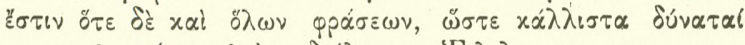

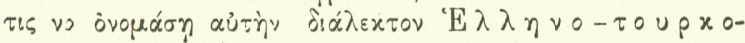

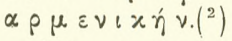

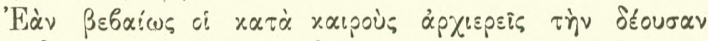

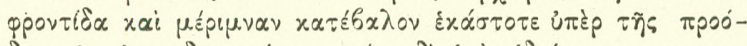

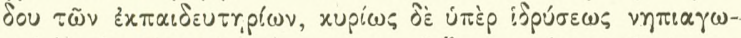

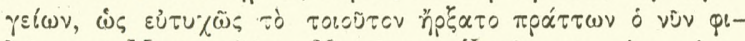

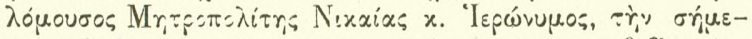

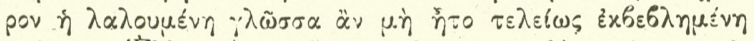

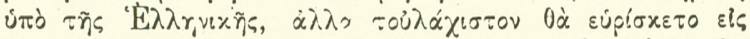

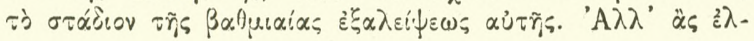

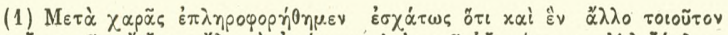

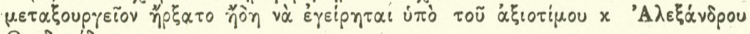
$\Theta \in 0 \delta \omega p i \delta 00$.

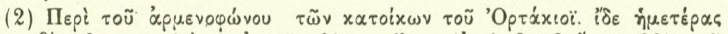

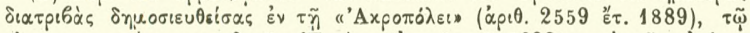

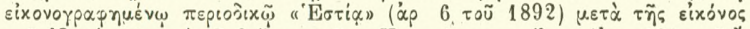

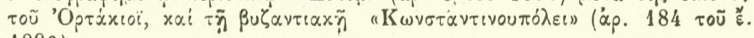
1890). 


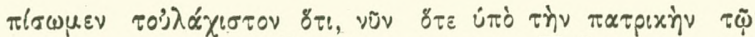

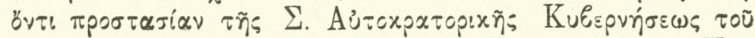

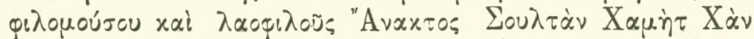

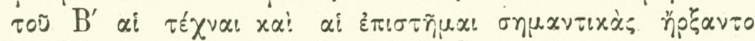

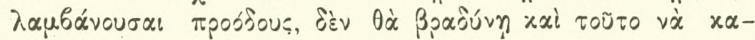
$\tau \circ \rho \theta \omega \theta \tilde{n}$.

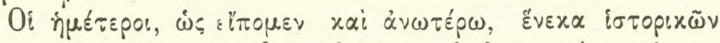

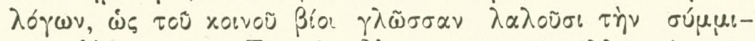

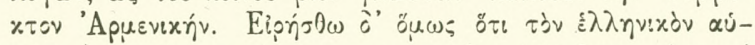

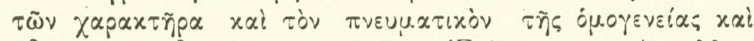

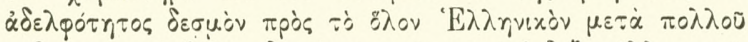

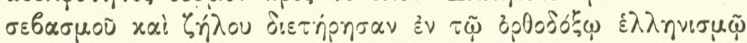

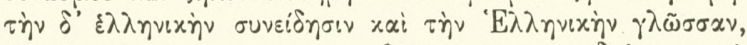

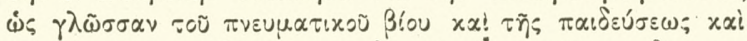

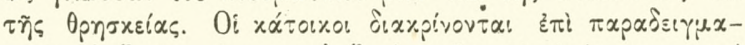

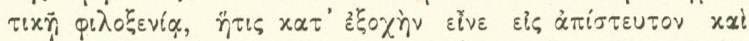

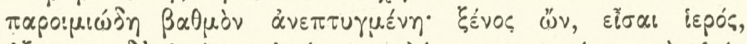

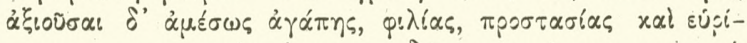

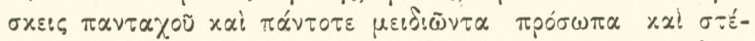

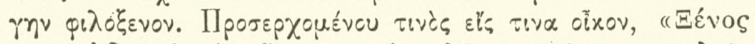

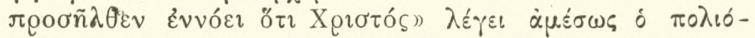

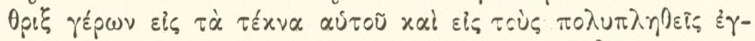

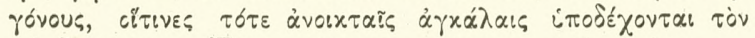

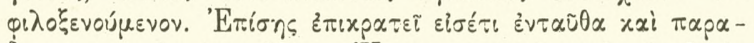

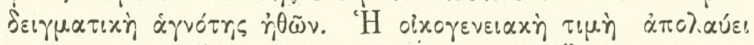

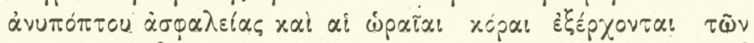

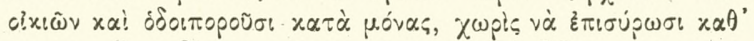

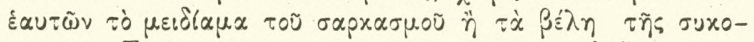

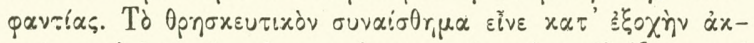

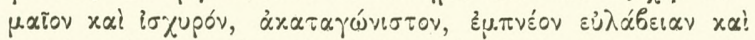

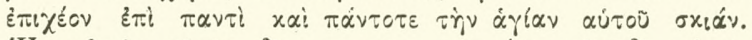

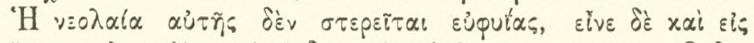

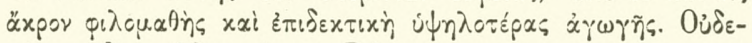

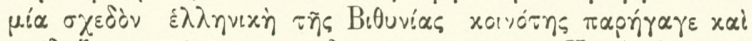

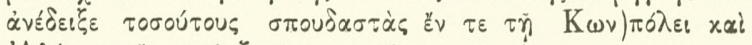

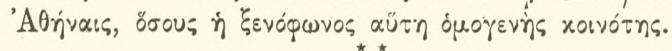




\section{$-10-$}

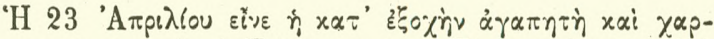

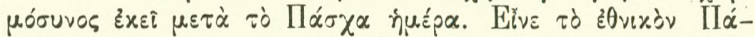

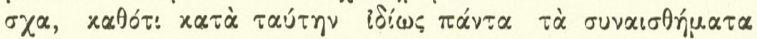

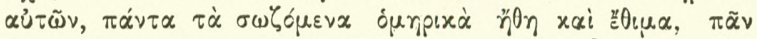

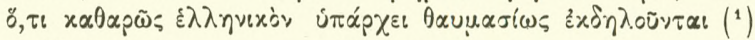

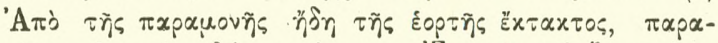

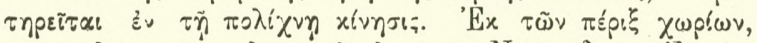

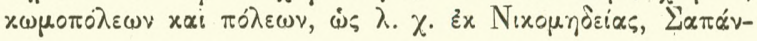

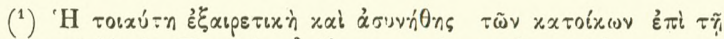

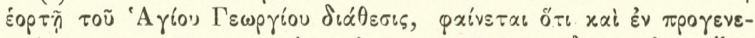

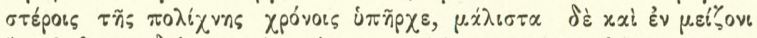

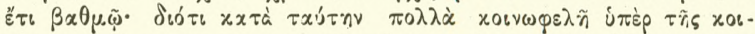
vó =n

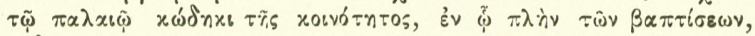

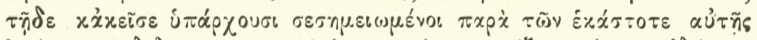

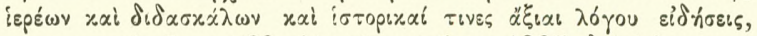

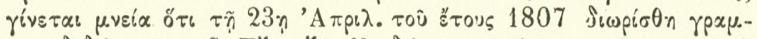

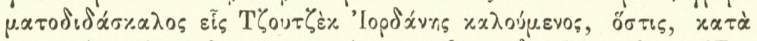

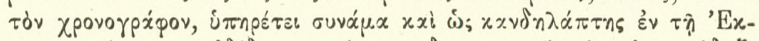

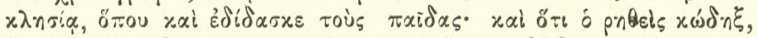

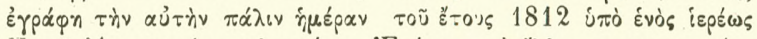

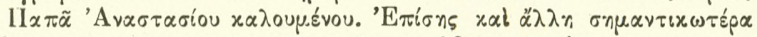

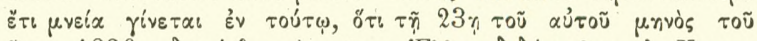

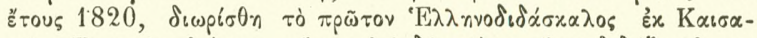

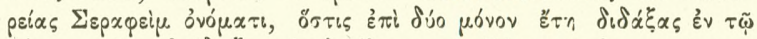

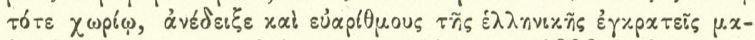

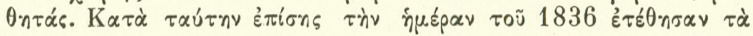

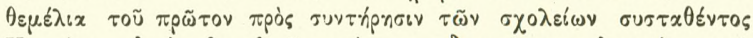

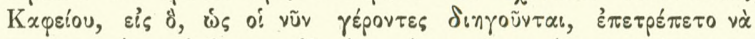

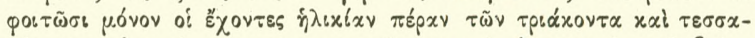

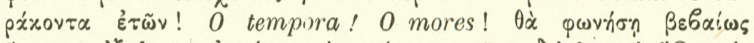

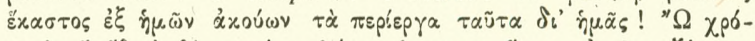

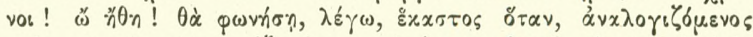

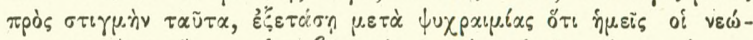

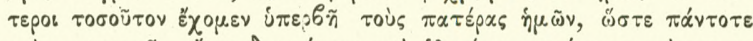

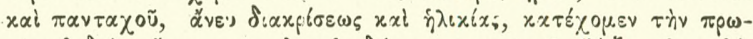

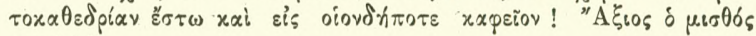
$\mu x_{5} ! ! ! \ldots$ 


\section{$-11-$}

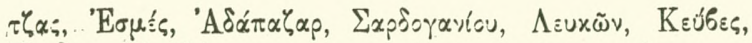

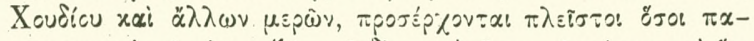

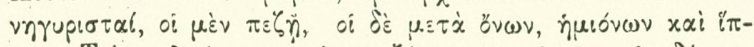

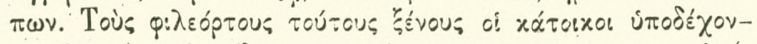

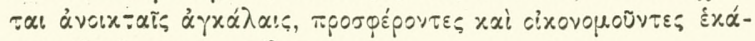

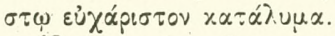

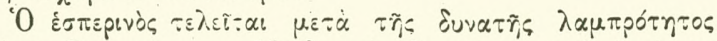

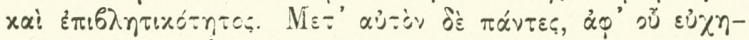

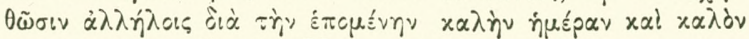

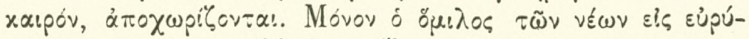

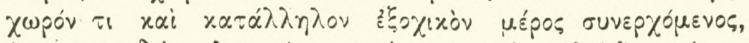

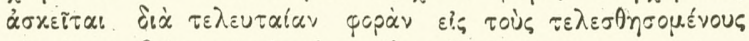

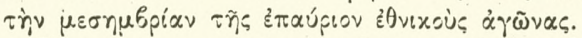

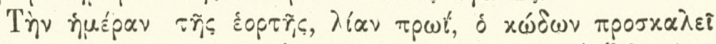

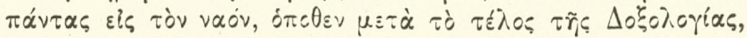

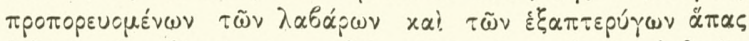

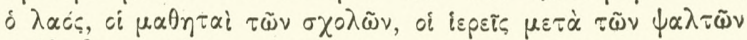

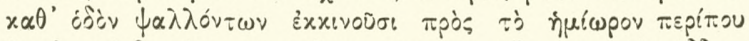

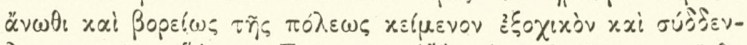

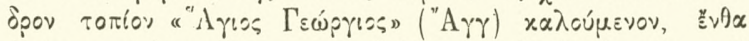

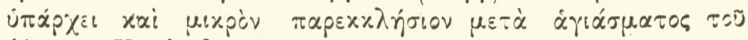

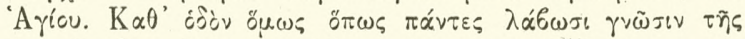

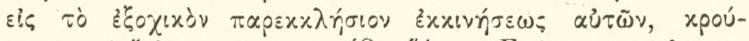

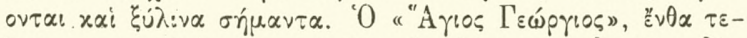

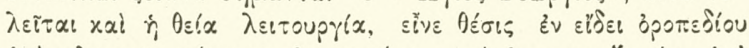

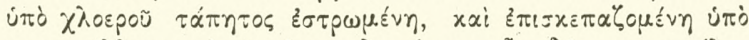

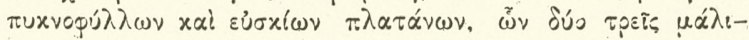

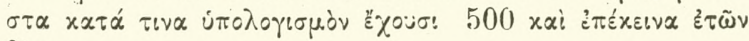
Biov.

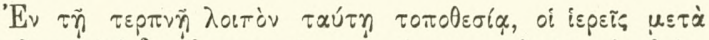

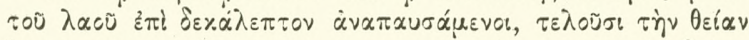

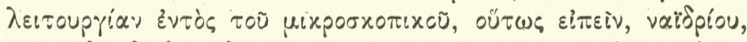

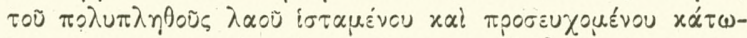

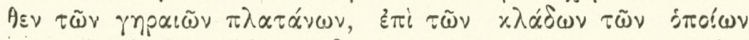

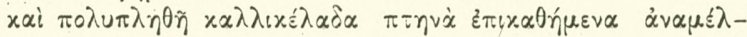

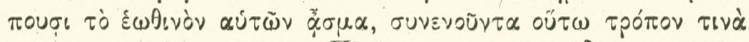

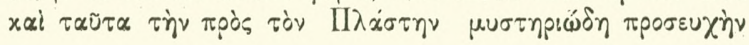




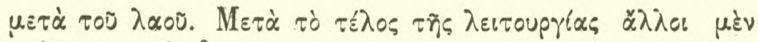

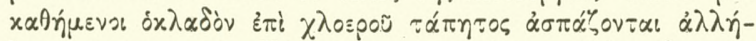

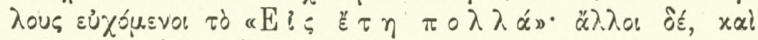

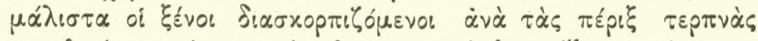

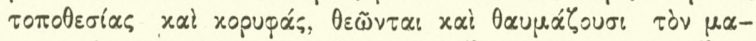

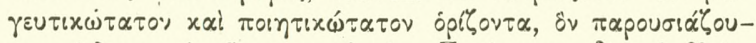

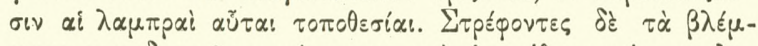

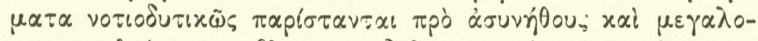

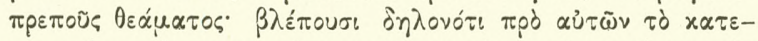

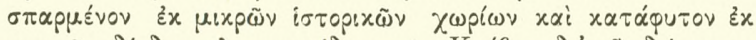

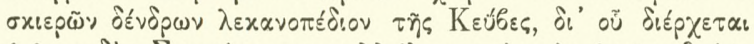

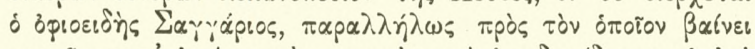

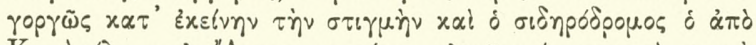

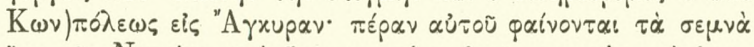

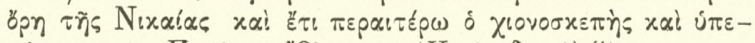

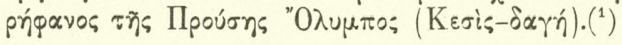

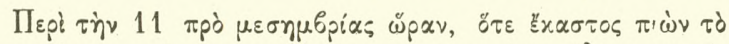

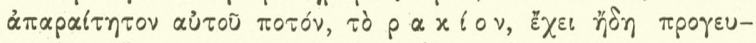

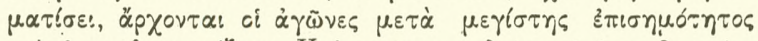

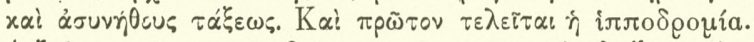

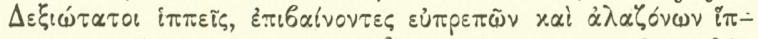

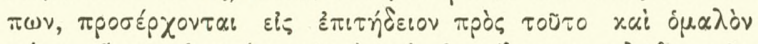

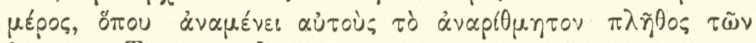

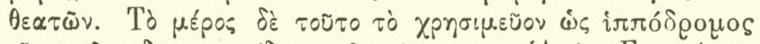

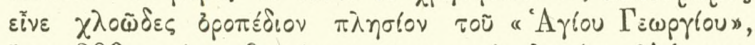

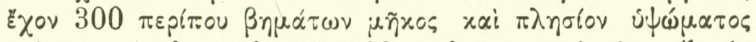

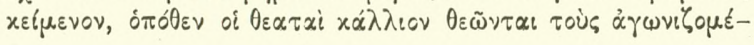

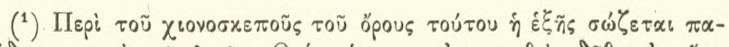

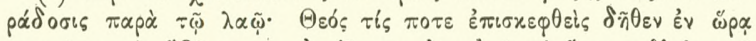

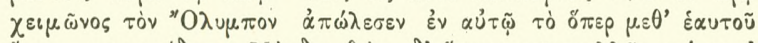
है

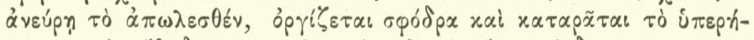

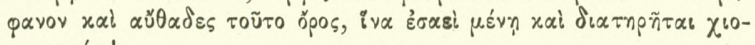
vоб $\times 8 \pi \dot{\varepsilon} \varsigma$ ! 


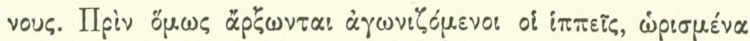

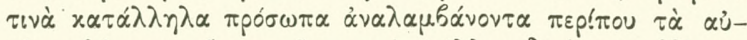

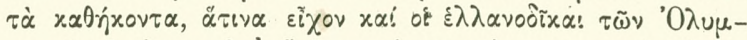

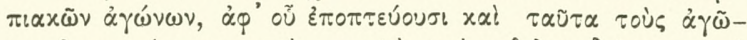

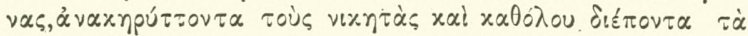

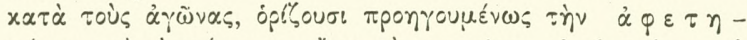

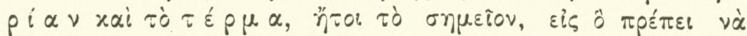

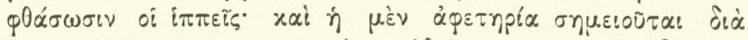

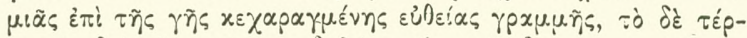

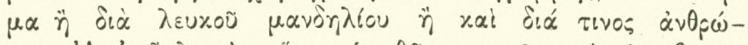

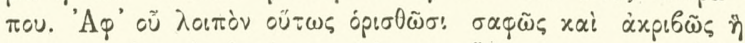

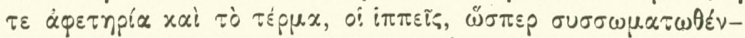

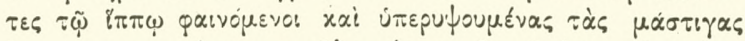

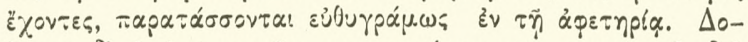

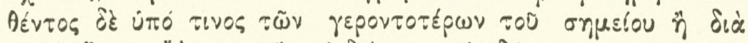

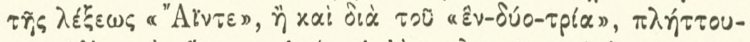

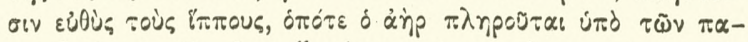

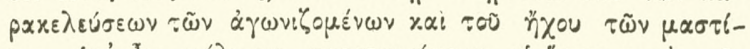

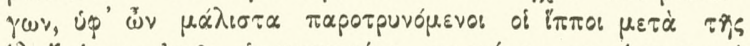

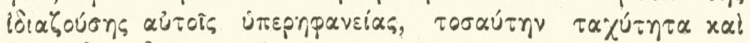

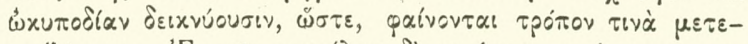

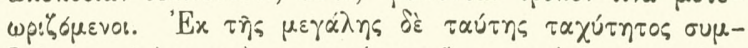

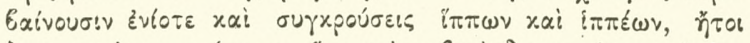

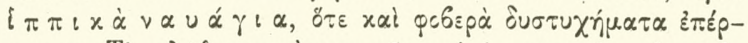

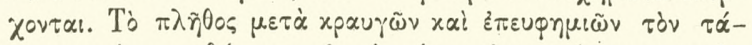

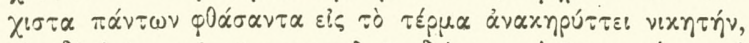

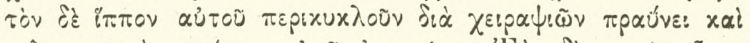

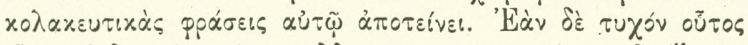

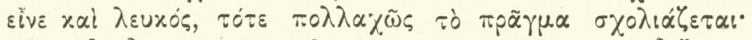

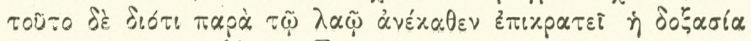

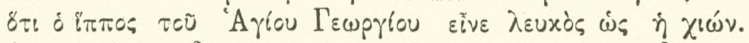

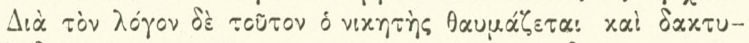

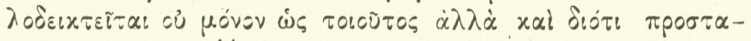

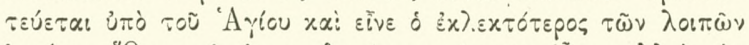

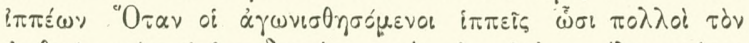

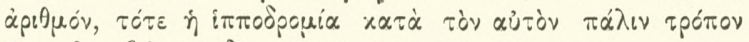

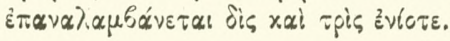




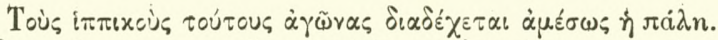

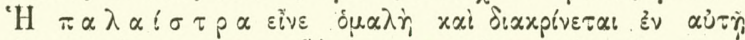

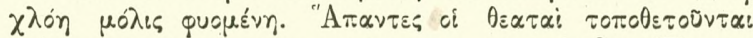

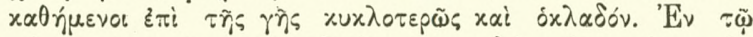

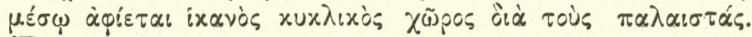

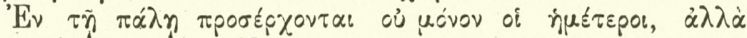

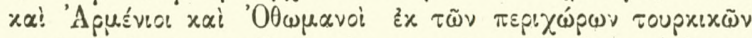

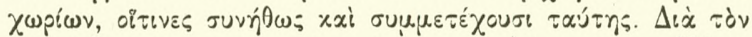

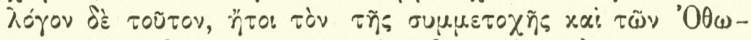

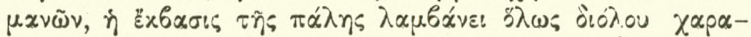

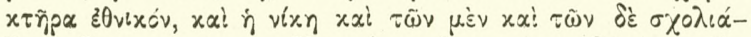

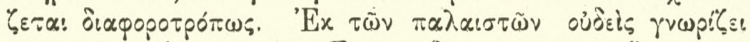

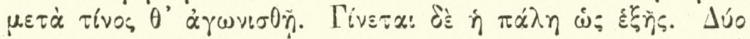

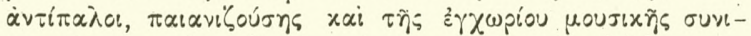

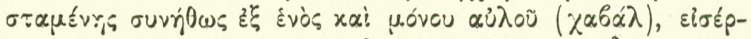

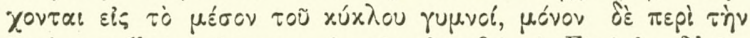

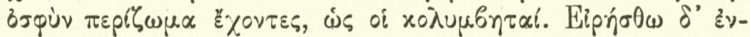

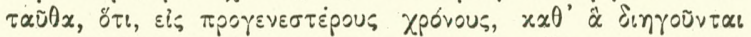

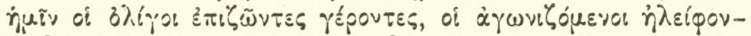

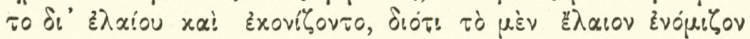

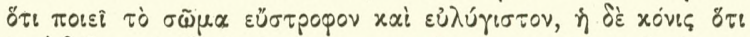

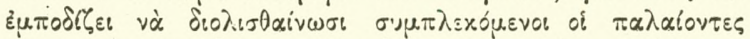

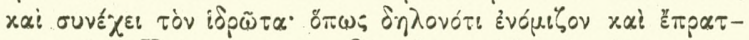

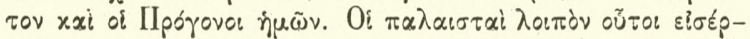

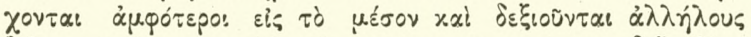

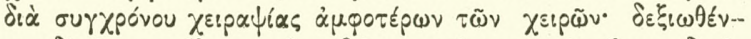

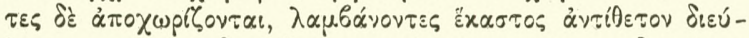

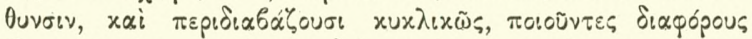

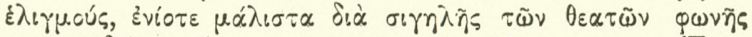

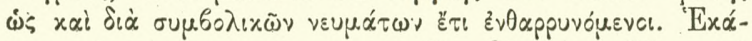

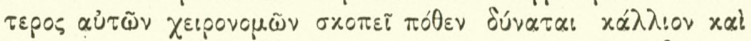

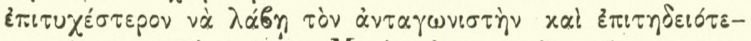

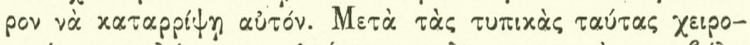

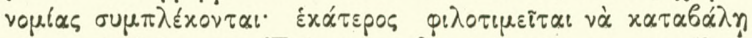

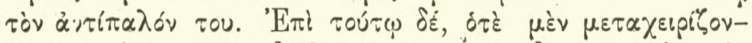

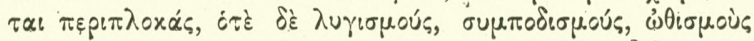

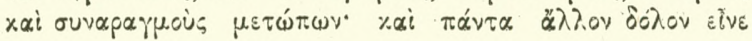




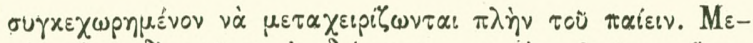

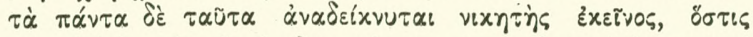

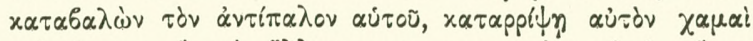

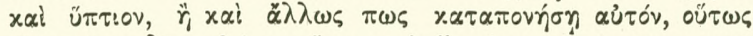

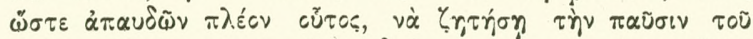

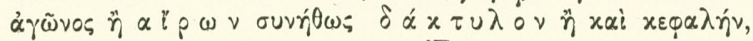

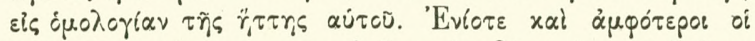

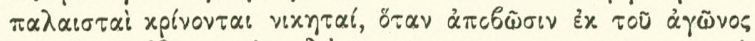

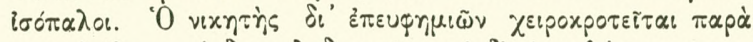

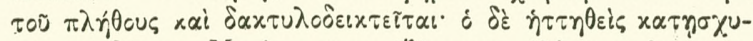

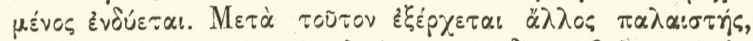

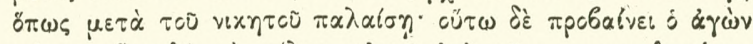

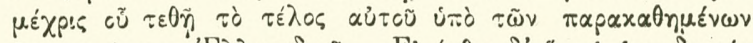

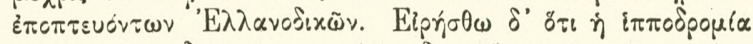

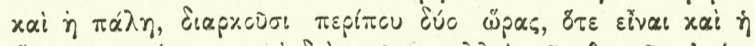

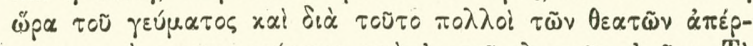

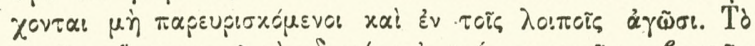

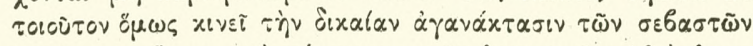

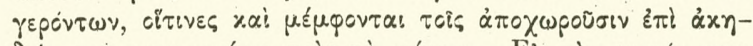

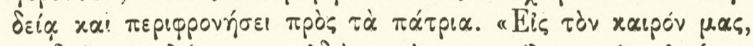

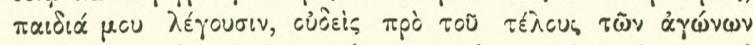

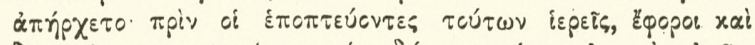

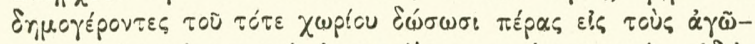

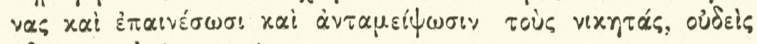

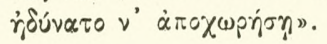

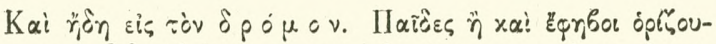

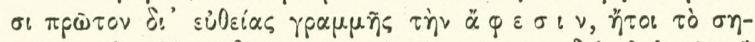

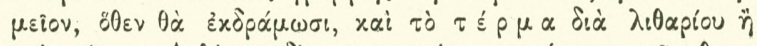

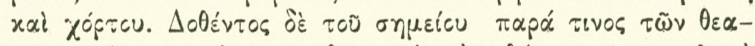

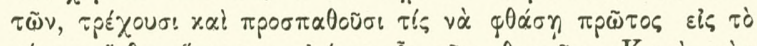

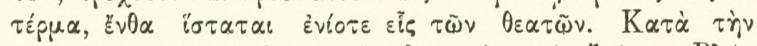

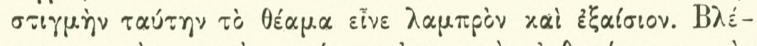

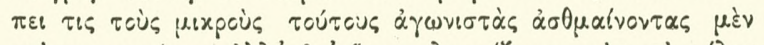

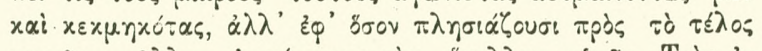

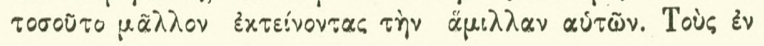




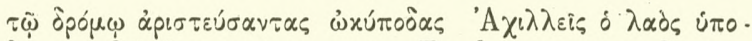

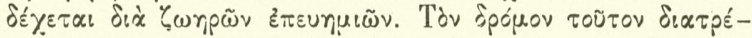

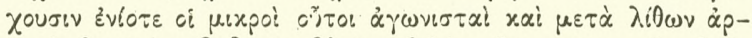

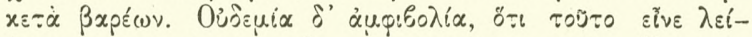

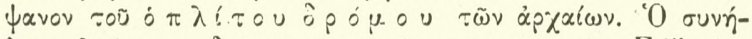

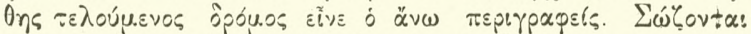

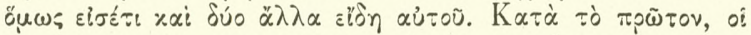

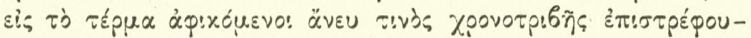

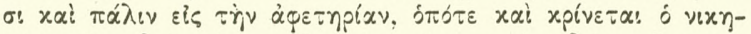

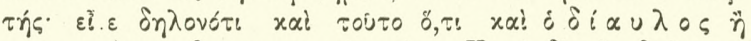

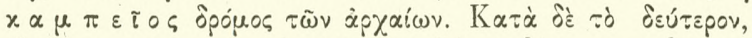

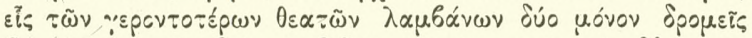

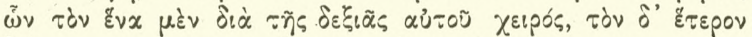

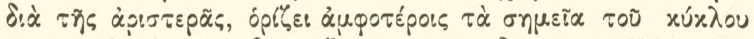

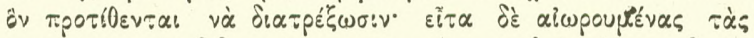

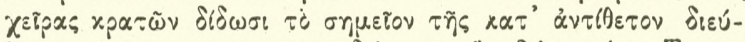

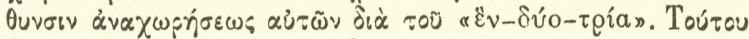

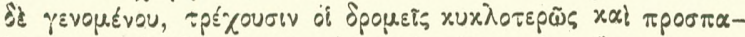

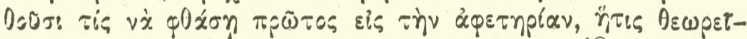

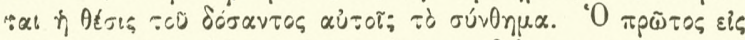

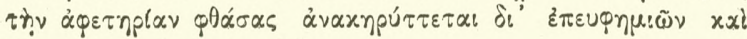

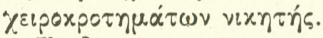

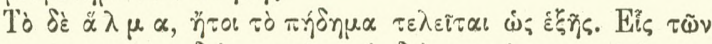

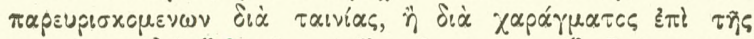

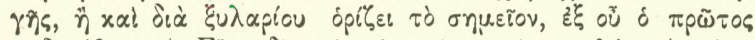

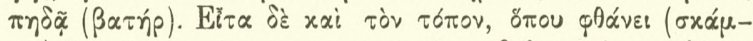

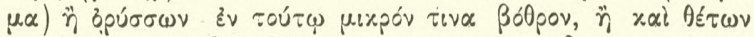

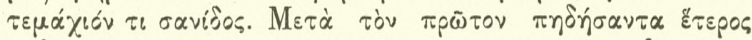

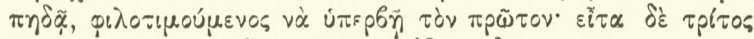

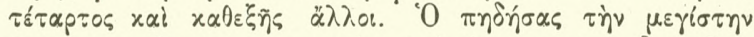

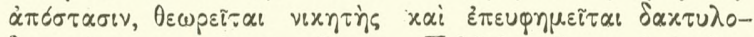

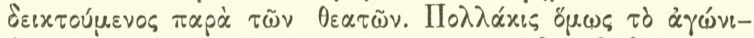

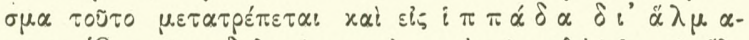

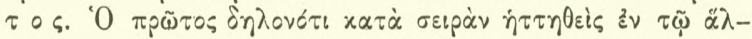

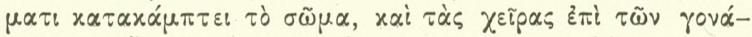

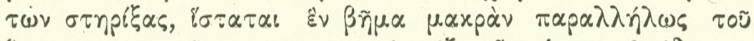

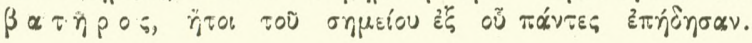




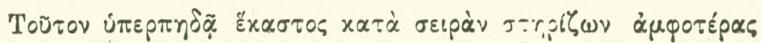

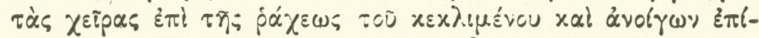

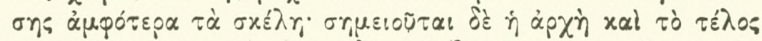

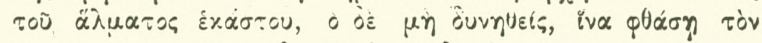

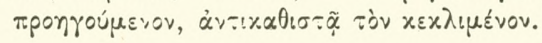

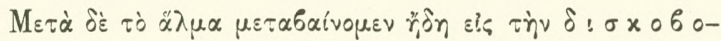

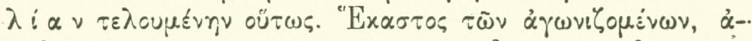

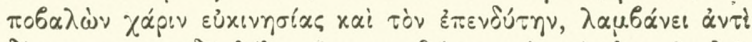

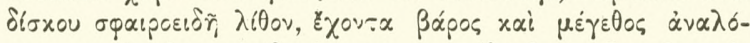

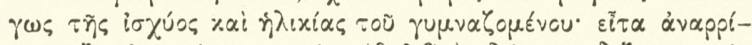

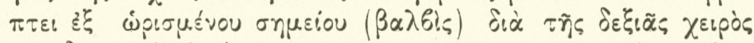

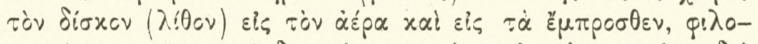

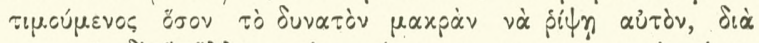

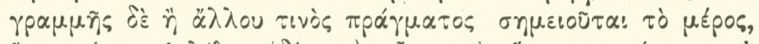

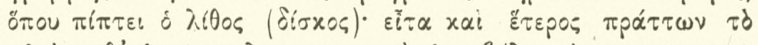

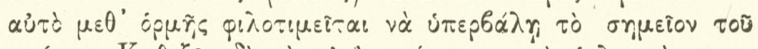

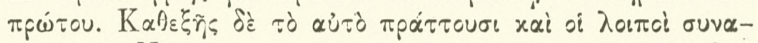

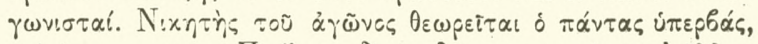

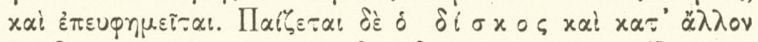

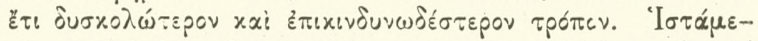

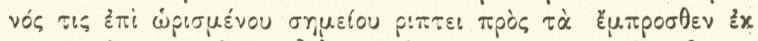

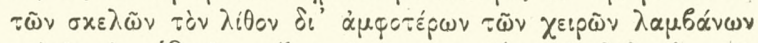

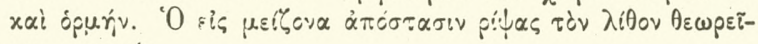

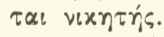

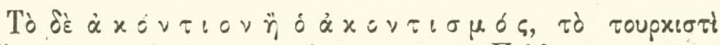

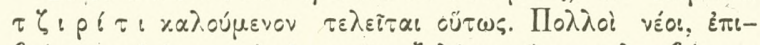

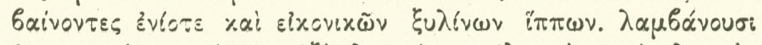

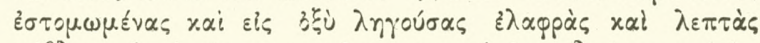

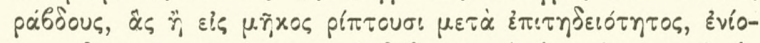

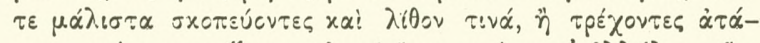

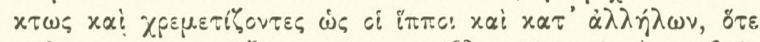

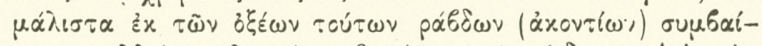

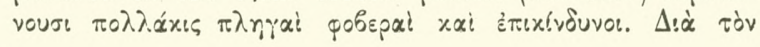




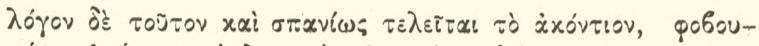

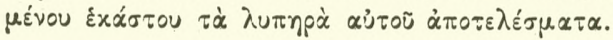

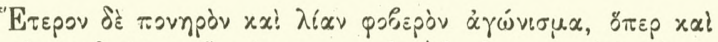

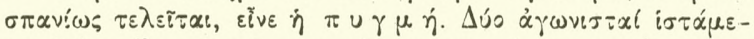

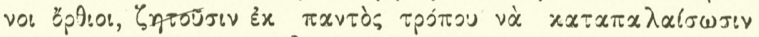

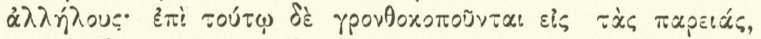

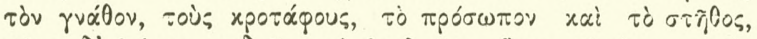

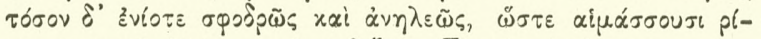

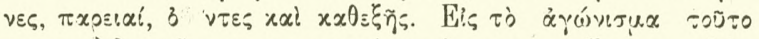

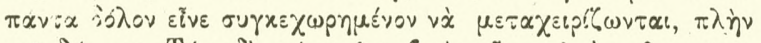

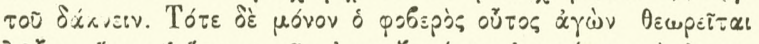

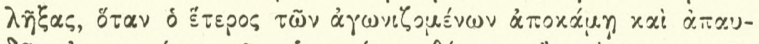

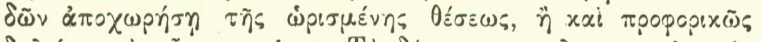

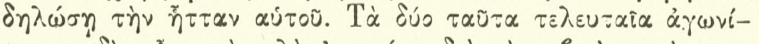

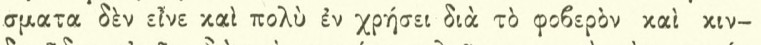

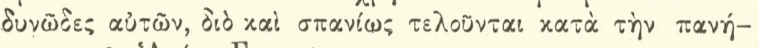

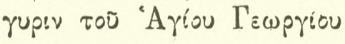

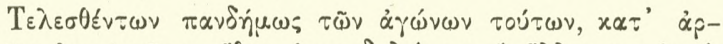

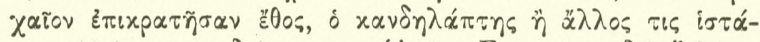

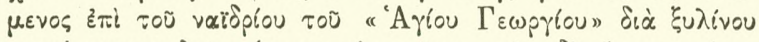

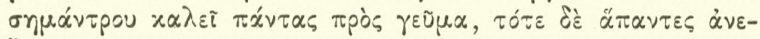

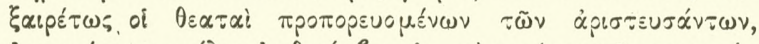

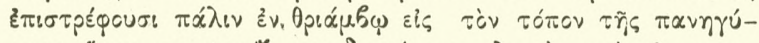

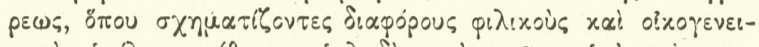

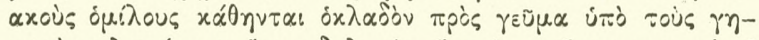

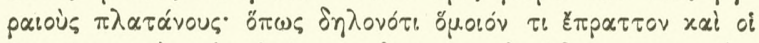

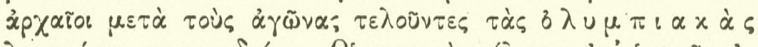

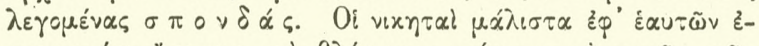

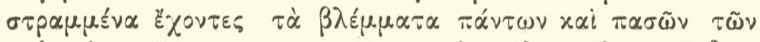

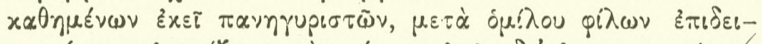

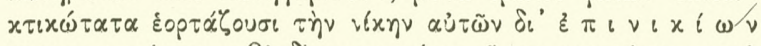

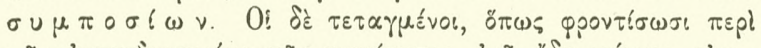

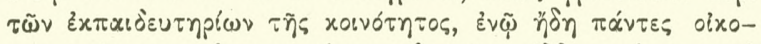

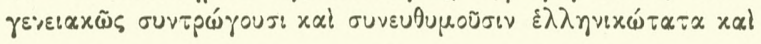




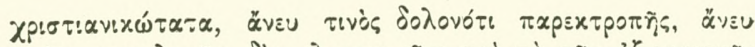

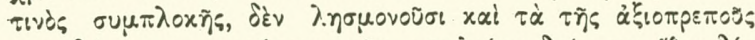

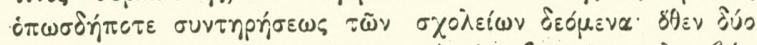

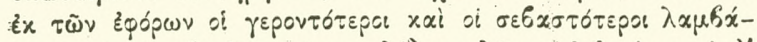

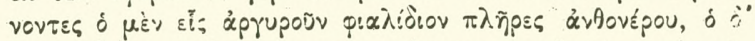

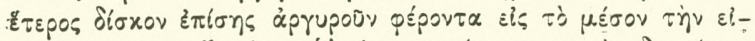

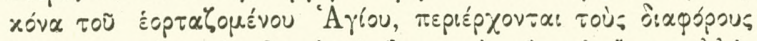

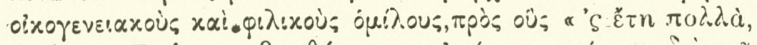

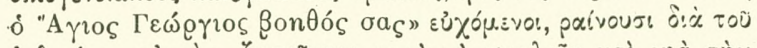

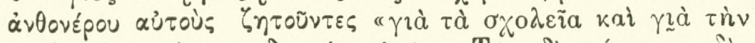

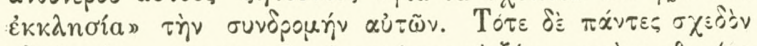

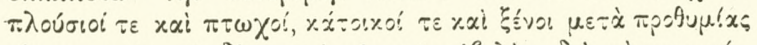

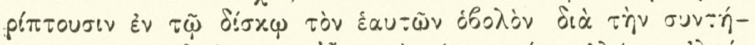

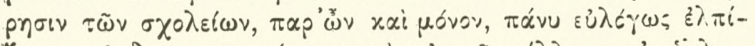

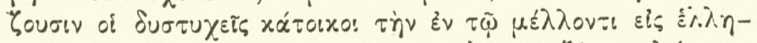

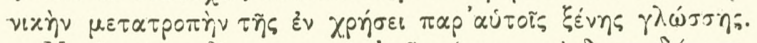

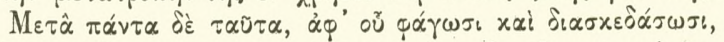

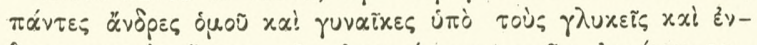

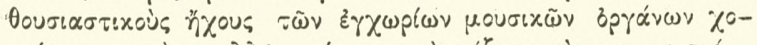

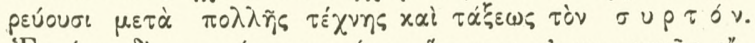

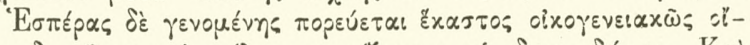

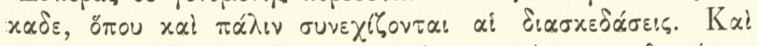

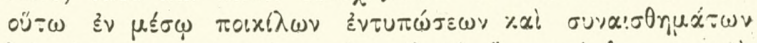

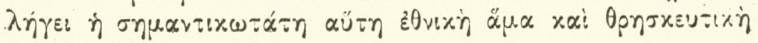

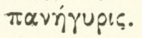

\section{Té́pyéos $\Delta$. Maxtéxos}

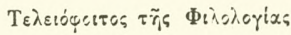

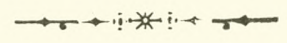

KENTPO MIKPAEIATIKQN ETOYAQN

IAPYMA MEATRE MEPAIE

B I B $\wedge$ I O О H K H 


\section{$\Sigma \mathrm{XO} \Lambda \mathrm{IO}$}

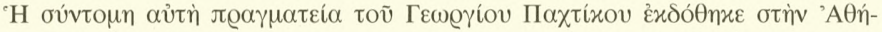

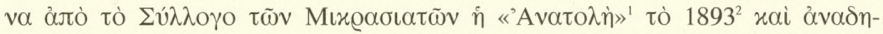

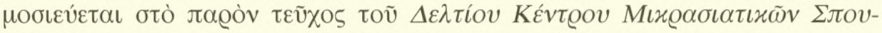

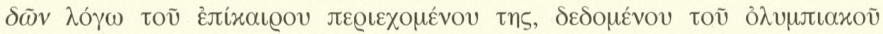

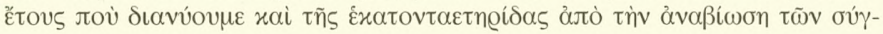

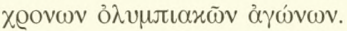

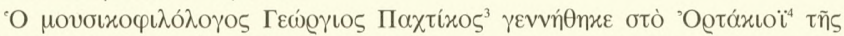

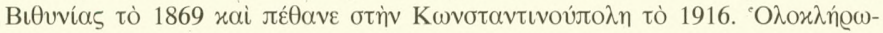

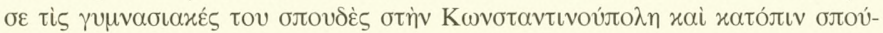

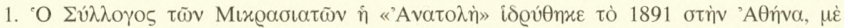

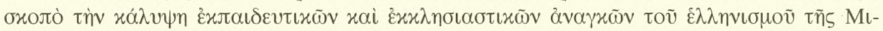

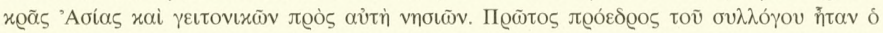

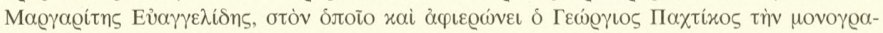

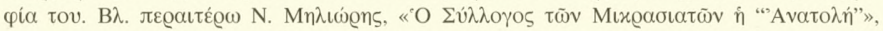

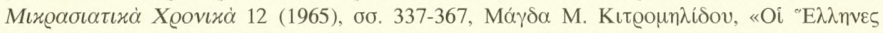

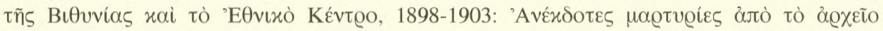

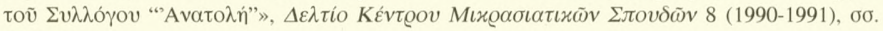
87-106.

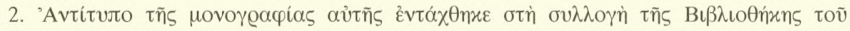

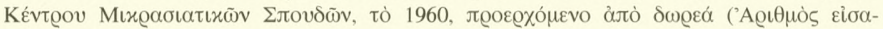
$\gamma \omega \gamma \tilde{n} \varsigma$ 1504).

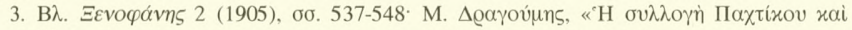

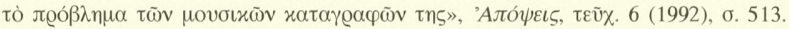

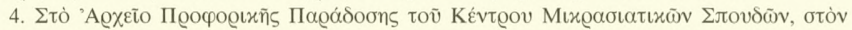

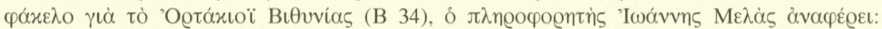

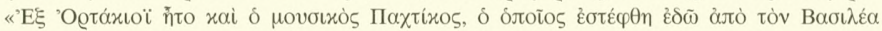

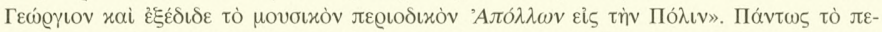

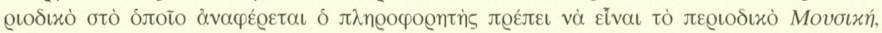

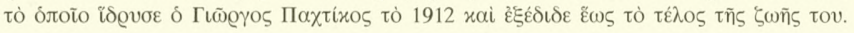




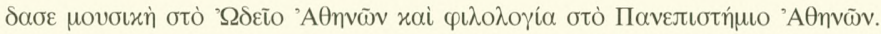

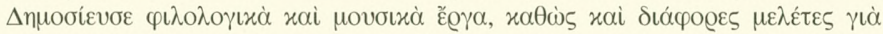

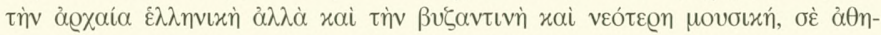

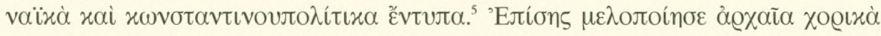

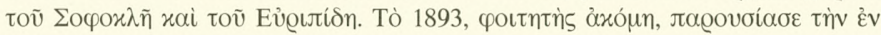

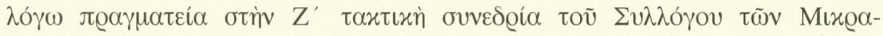

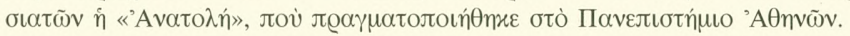

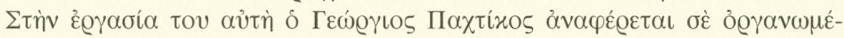

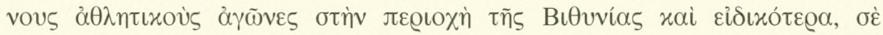

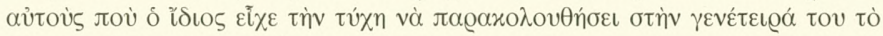

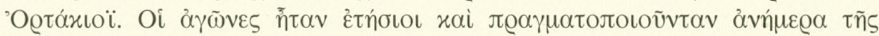

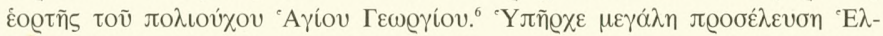

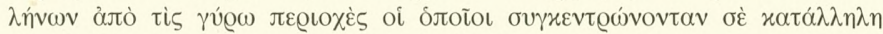

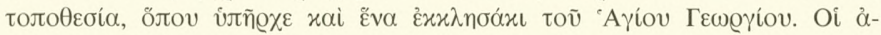

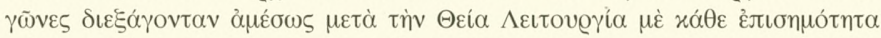

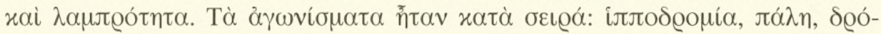

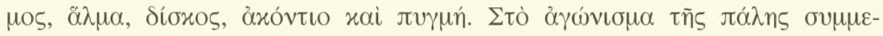

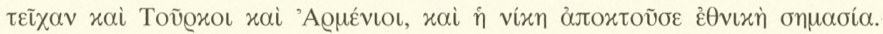

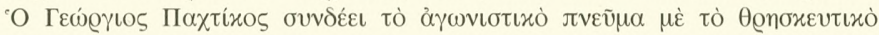

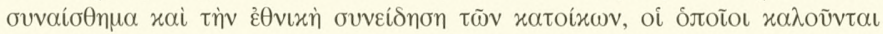

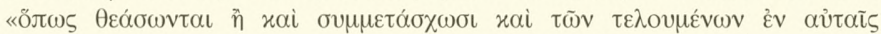

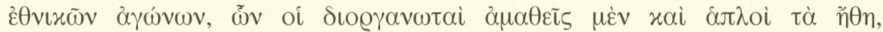

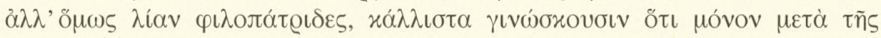

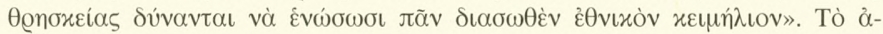

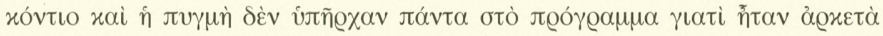

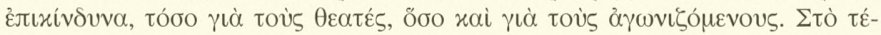

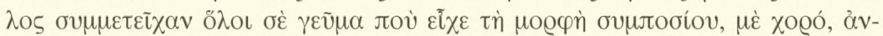

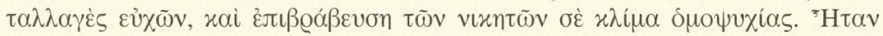

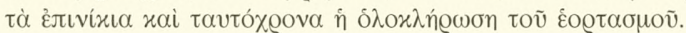

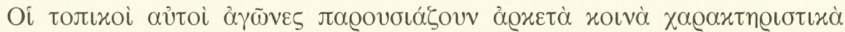
$\mu \varepsilon \dot{~} \tau$ où

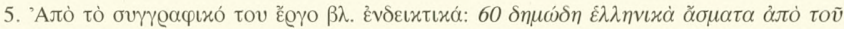

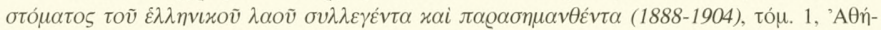

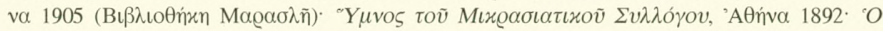

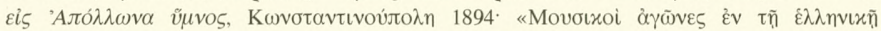

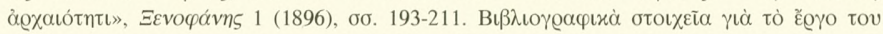

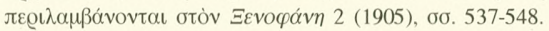

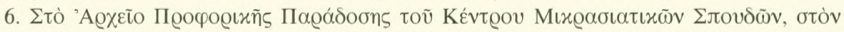

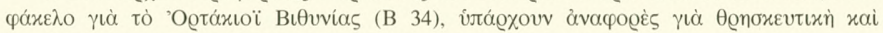

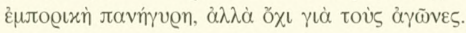




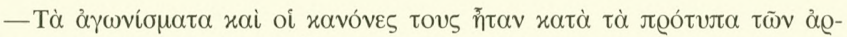

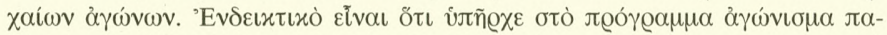

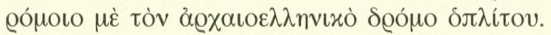

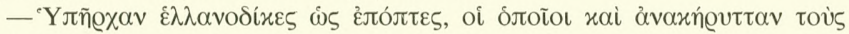

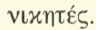

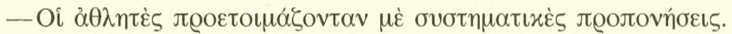

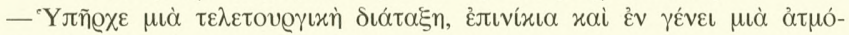

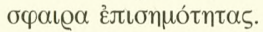

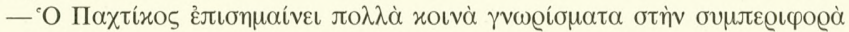

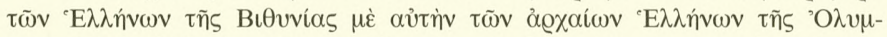

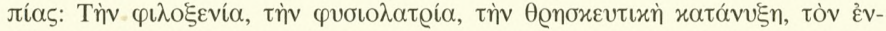

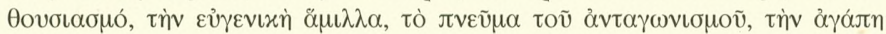

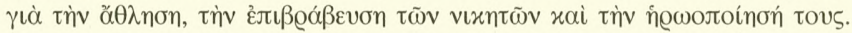

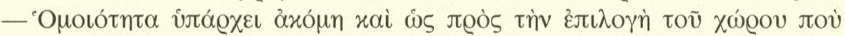

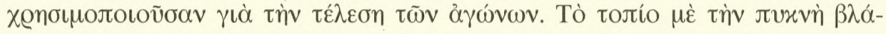

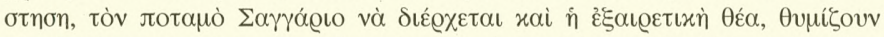

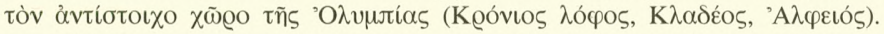

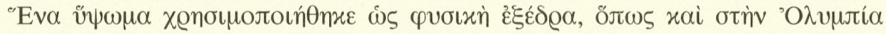

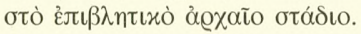

$\triangle \mathrm{IONY} \Sigma \mathrm{H} \Sigma \mathrm{M}$. KOKKINO $\Sigma$ 